Walkyria Lara, química, pesquisadora científica

da Seção de Aditivos e Resíduos de Pesticidas do Instituto Adolfo Lutz, responsável pelo

Centro Colaborador do Programa Conjunto

FAO/OMS para Monitoramento da

Contaminação de Alimentos e coordenadora dos Encontros Nacionais de Analistas de

Resíduos de Pesticidas.

\title{
A presença do DDT no leite materno
}

Entre o grande número de substâncias químicas que foram introduzidas para melhoria da produção agrícola, os chamados defensivos agrícolas foram, sem dúvida alguma, de importância no cambate às pragas e muito contribuíram para o aumento da produção de alimentos.

Os anos pós-guerra foram de muita pesquisa e desenvolvimento de produtos orgânicos com poder inseticida como o BHC, O DDT, aldrin, endrin, dodecacloro e outros.

O fato desses compostos serem poucos reativos, de difícil degradação, os torna persistentes, isto é, duram por vários anos no solo das culturas em que foram aplicados, e vão se acumulando na cadeia alimentar. Isto levou a um estudo dessas substâncias nos alimentos e no meio ambiente.

Como o homem está no fim da cadeia alimentar é importante examinar os níveis desses compostos nos fluidos biológicos e tecidos adiposos. Vários países vêm desenvolvendo estudos a esse respeito e os resultados servem como indicadores da contaminação das populações, causada pela poluição do ambiente e principalmente pela contaminação dos alimentos.

O leite materno constitui para o recém-nascido o melhor dos alimentos, oferecendo vantagens, além daquelas nutritivas, como o aumento da resistência às infecções, pela passagem dos anticorpos da mãe

\section{T no leite}


até abandonaram o uso de organoclorados continuam esse controle, pois há uma estabilização dos níveis.

No Brasil, infelizmente não há um monitoramento desse tipo de análise de BHC e DDI em alimentos e muito menos em leite humano.

Os primeiros levantamentos publicados de resíduos em leite de vaca e outros alimentos datam de $1971^{2}$. Era de se esperar que também no leite humano se encontrassem resíduos desse tipo. Assim, não constituiu surpresa os resultados de uma pesquisa realizada com a equipe do setor de resíduos de pesticidas da Seção de Aditivos do Instituto Adolfo Lutz, durante os anos de 1979 e 1981, o qual foi publicado em 1982 na Revista do Instituto Adolfo Lutz ${ }^{3}$.

Em 25 amostras analisadas, todas apresentaram níveis variados de isômeros de $\mathrm{BHC}$ (hexaclorociclohexano) e do pp'DDE (metabolito do DDT). Os níveis do $\mathrm{BHC}$ (soma dos isômeros) variaram de 3 a 758 microgramas por litro (partes por bilhão) com média de 49 microgramas por litro, sendo que apenas duas amostras estavam com níveis acima de 100 microgramas por litro. Em relação aơDDT (soma do metabolito pp'DDEe isômeros), a variação foi de 15 a 2.610 microgramas por litro. Este valor extremamente alto correspondeu ao do valor mais alto de BHC (758) e pertence a amostra de uma pessoa que trabalhou no meio rural em contato direto com os produtos.

A comparação dos resultados encontrados com o de outros estudos em outros países é bastante difícil, pois as amostras examinadas são em pequeno número e não é representativa sequer da totalidade da população brasileira. Em relação a dados dos relatórios do Programa Conjunto FAO/OMS de Monitoramento da Contaminação de Alimentos ${ }^{4}$, que cobrem os anos 71 a 75 e apresentam os valores das medianas dos resultados encontrados, a nossa situação é melhor que a do Japão e Estados Unidos, em relação ao BHC, e melhor que a dos Estados Unidos e mais elevado que a do Japão, em relação ao DDT.

A razão destes levantamentos é importante porque, como já foi dito, eles revelam o grau de contaminação na população por produtos que devem ser cada vez mais regulamentado ou mesmo ter restringido o seu uso.

Por serem cumulativos é importante monitorar os níveis de contaminação no leite materno para verificar a tendência dos mesmos, se diminuem em resposta às precauções e regulamentações impostas ao uso ou não. Se são substâncias xenobióticas, isto é, estranhas aos processos vitais, é necessário saber quais as conseqüências das mesmas nos organismos em formação.

Talvez nenhum xenobiótico tenha sido tão estudado quanto o DDT. A controvérsia sobre se é cancerígeno ou não, é bastante grande e não se tem até hoje nenhuma evidência suficiente para dizer que é causador de tumores em humanos ${ }^{5}$. Claro que não é preciso esta evidência para tornar-se indesejável ao organismo, e principalmente ao organismo em formação, uma substância que não sabemos exatamente o que irá acarretar de interferências no mesmo. Daí ser importante o conhecimento dos níveis existentes na população e principalmente quanto o recém-nascido está ingerindo através do leite materno.

\section{Referências bibliográficas}

1. LAUG, E.P. et alii. Occurrence of DDT in human fat and milk. Archive of Industrial Higyene Occupational Medicine, 3: 245-6, 1951

2. ALMEIDA, M.E.W. \& BARRETO, H.H.C. Resíduos de pesticidas clorados em leite consumido em São Paulo. Rev. do Instituto Adolfo Lutz. 31: 13-20, 1971.

3. LARA, W.H. et alii. Resíduos de pesticidas clorados em conservas de carne bovina. São Paulo, Rev. do Instituto Adolfo Lutz, 31: 63-70, 1971.

4. LARA, W.H. Resíduos de pesticidas organoclorados em leite humano. São Paulo, Rev. do Instituto Adolfo Lutz, 42(1/2): 45-52, 1982.

5. JOINT/FAO/WHO. Food and animal food contamination monitoring programme; Phase 11. Summary report of data received from collaborating centres for food contamination monitoring, 1978. IFAO: ESN/MON/78.2. WHO: HCS/FCM/78.2)

6. IARC. Some halogenated hydrocarbons. S.I. IARC, 1979. Monographs on the Evaluation of the Carcinogenic Risk to Humans, 20. 